\title{
Albumin, bilirubin, uric acid and cancer risk: results from a prospective population-based study
}

\author{
Tilman Kühn ${ }^{\star},{ }^{,}$, Disorn Sookthai ${ }^{1}$, Mirja E Graf ${ }^{1}$, Ruth Schübel ${ }^{1}$, Heinz Freisling ${ }^{2}$, Theron Johnson ${ }^{1}$, \\ Verena Katzke ${ }^{1}$ and Rudolf Kaaks ${ }^{1}$ \\ ${ }^{1}$ German Cancer Research Center (DKFZ), Division of Cancer Epidemiology, Im Neuenheimer Feld 280, Heidelberg D-69120, \\ Germany and ${ }^{2}$ International Agency for Research on Cancer, Section of Nutrition and Metabolism, International Agency for \\ Research on Cancer (IARC-WHO), 150 Cours Albert Thomas, Lyon 69008, France
}

Background: It has long been proposed that albumin, bilirubin and uric acid may inhibit cancer development due to their antioxidative properties. However, there is a lack of population-based studies on blood levels of these molecules and cancer risk.

\begin{abstract}
Methods: Associations between pre-diagnostic serum albumin, bilirubin and uric acid and the risks of common cancers as well as cancer death in the EPIC-Heidelberg cohort were evaluated by multivariable Cox regression analyses. A case-cohort sample including a random subcohort $(n=2739)$ and all incident cases of breast $(n=627)$, prostate $(n=554)$, colorectal $(n=256)$, and lung cancer $(n=195)$ as well as cancer death $(n=761)$ that occurred between baseline (1994-1998) and 2009 was used.
\end{abstract}

Results: Albumin levels were inversely associated with breast cancer risk (hazard ratio Quartile 4 vs Quartile 1 (95\% Cl): 0.71 (0.51, 0.99), $\left.P_{\text {linear trend }}=0.004\right)$ and overall cancer mortality $\left(\mathrm{HR}_{\mathrm{Q} 4}\right.$ vs $\mathrm{Q}_{1}(95 \% \mathrm{Cl}): 0.64(0.48,0.86), P_{\text {linear }}$ trend $\left.<0.001\right)$ after multivariable adjustment. Uric acid levels were also inversely associated with breast cancer risk (HR $\mathrm{Q}_{\mathrm{Q}}$ vs Q1 $(95 \% \mathrm{Cl})$ : $0.72(0.53,0.99)$, $\left.P_{\text {linear trend }}=0.043\right)$ and cancer mortality $\left(H_{Q_{Q}}\right.$ vs $Q_{1}(95 \% \mathrm{Cl}): 0.75(0.58,0.98), P_{\text {linear }}$ trend $\left.=0.09\right)$. There were no significant associations between albumin or uric acid and prostate, lung and colorectal cancer. Serum bilirubin was not associated with any cancer end point.

Conclusions: The present findings indicate that higher levels of albumin and uric acid are related to lower risks of breast cancer and cancer mortality. Further studies are needed to assess whether the observed associations are causal.

It has long been proposed that endogenous antioxidants, particularly albumin, bilirubin and uric acid, may exert anticarcinogenic properties (Ames et al, 1981; Stocker et al, 1987; Halliwell, 1988; Ko et al, 1994). Indeed, various clinical cohort studies have shown that lower levels of albumin prior to therapy are related to worse outcomes in cancer patients with different types of tumours (Gupta and Lis, 2010). Concerning uric acid and bilirubin, findings from prognosis studies are less consistent, with some pointing to better outcomes in cancer patients with higher blood levels (Ching et al, 2002; Zucker et al, 2004; Lin et al, 2013;
Dziaman et al, 2014; Liu et al, 2015) and others suggesting the opposite (Shin et al, 2006; Haas et al, 2013; Stotz et al, 2014; Gao et al, 2016).

Previous prospective studies on pre-diagnostic levels of circulating antioxidants and cancer risk have revealed mixed results. In three cohort studies, serum albumin levels were inversely associated with cancer mortality (Phillips et al, 1989; KlonoffCohen et al, 1992; Fischer et al, 2014). The only other cancer end point, for which data from more than one prospective study exists, is colon cancer; while three studies showed inverse associations

*Correspondence: Dr T Kühn; E-mail: t.kuehn@dkfz.de

Received 9 June 2017; revised 5 August 2017; accepted 11 August 2017; published online 12 September 2017

(C) 2017 Cancer Research UK. All rights reserved 0007 - 0920/17 
with albumin (Stevens et al, 1988; Ko et al, 1994; Ghuman et al, 2017), and two showed no associations (Knekt et al, 2000; Prizment et al, 2011), three further prospective studies did not reveal associations between albumin and the risks of breast (Wulaningsih et al, 2015), prostate (Van Hemelrijck et al, 2011) and lung cancer (Sprague et al, 2008).

Baseline levels of bilirubin were inversely associated with total cancer mortality in a population-based cohort from Belgium (Temme et al, 2001). In addition, inverse associations between prediagnostic bilirubin levels and lung cancer risk were reported from two prospective studies (Horsfall et al, 2011; Wen et al, 2015), whereas bilirubin levels were not related to colon cancer risk in two smaller studies (Ko et al, 1994; Ioannou et al, 2006).

With respect to uric acid, a recent meta-analysis based on nine prospective studies pointed to a direct relationship with overall cancer mortality, even though significant heterogeneity of results from the included studies was reported (Yan et al, 2015). Studies on uric acid levels and cancer incidence have provided mixed results. In a smaller cohort of Japanese men from Hawaii, uric acid levels were positively associated with the risk of prostate cancer but no other cancer types (Kolonel et al, 1994). A large-scale study from Austria showed that pre-diagnostic uric acid levels were related to an increased risk of overall cancer, and particularly cancers of the digestive and urinary organs as well as haematopoietic cancers in men (Strasak et al, 2009), and cancer mortality in women (Strasak et al, 2007). Similarly, uric acid levels were associated with an increased overall cancer risk in clients of an American health maintenance organisation (Hiatt and Fireman, 1988). By contrast, an evaluation of a large British primary care database revealed that uric acid levels were inversely associated with lung cancer risk, although this association was limited to smokers (Horsfall et al, 2014). No association between uric acid levels and colon cancer risk were found in a smaller prospective study from the United States (Ko et al, 1994).

In several of the above-mentioned studies, secondary data from health insurances and primary care were used for statistical analyses and a detailed adjustment for potential confounders was not possible. Thus and considering the low number of prospective studies on serum antioxidants and individual cancer types, we decided to comprehensively investigate whether albumin, bilirubin and uric acid levels are associated with the risk of the most common cancers in a well-characterised population-based cohort. Following a case-cohort design, serum biomarkers were measured in samples of participants, who developed breast, prostate, lung and colorectal cancer or died of cancer (all cancers), and participants selected for a large random subcohort.

\section{METHODS}

Study population. EPIC-Heidelberg is part of the European Prospective Investigation into Cancer and Nutrition (EPIC), an ongoing multicentre cohort study in 23 study centres across 10 European countries that was launched in the 1990s (Riboli and Kaaks, 1997). In Heidelberg, 25540 volunteers (53\% women) from the local general population in the age range between 35 and 65 years entered the study between 1994 and 1998 (Boeing et al, 1999). The baseline examination included a medical interview and detailed assessments of socio-economic status, dietary habits, tobacco use and alcohol consumption. In addition, anthropometric measurements were taken and a blood sample was obtained for the biobank of the study. Since the baseline of EPIC-Heidelberg, participants are being followed-up by active and passive procedures. Incident cases of cancer are ascertained by study physicians and validated against medical records (Bergmann et al, 1999). Death cases are recorded via record linkage and death certificates are used to code causes of death. The study was approved by the ethics committee of the Heidelberg University Hospital and all participants provided written informed consent.

For the present analyses on blood antioxidants and cancer risk, a case-cohort sample was chosen. This sample consists of a random subcohort $(n=2739)$ and all incident cases of breast (ICD-10 C50, $n=627$ ), prostate (ICD-10 C61, $n=554$ ), lung (ICD-10 C34, $n=195$ ) and colorectal cancer (ICD-10 C18-19, $n=256)$ as well as all cases of cancer death $(n=761)$ that had occurred until 31 December 2009, the closure date for the present study.

Laboratory methods. Blood samples were processed into plasma, serum, buffy coat and erythrocyte samples at baseline and stored in liquid nitrogen at $-196^{\circ} \mathrm{C}$. For the present analyses, serum straws were retrieved from the biobank, opened by a heated wire cutting system and aliquoted directly into measurement tubes. Serum samples were then delivered to the SHL Laboratories (Etten-Leur, The Netherlands) on dry ice, where serum concentrations of albumin, bilirubin and uric acid were determined using the Cobas 6000 analytical system (Roche Diagnostics, Mannheim, Germany) for clinical chemistry according to the manufacturer's protocols. Percentages of failed measurements were $2.8 \%, 8.2 \%$, and $7.8 \%$ for albumin, bilirubin and uric acid, respectively.

Statistical analyses. Mean values (s.d.) of covariates and frequencies of covariate strata are presented by case status to characterise the study population. In addition, geometric means of antioxidant levels adjusted for age and sex across strata of covariates were calculated by linear regression models. Associations between biomarker levels and end points (breast, prostate, colorectal and lung cancer as well as cancer death) were analysed by Cox proportional hazards regression models accounting for the casecohort design by the so-called Prentice method (Prentice, 1986). Age at baseline was used as age at entry and observations in the subcohort were censored at the end of follow-up, loss to follow-up, date of death or date of cancer diagnosis, whichever came first. According to the weighting scheme proposed by Prentice, cases outside the subcohort were only included into the risk set at the time of cancer diagnosis (Prentice, 1986). Extended correlation tests based on Schoenfeld residuals did not point to violations of the proportional hazards assumption (Xue et al, 2013). Two Cox regression models were used to evaluate associations between biomarkers and cancer risk. In a first 'crude' model, we only adjusted for sex and for age at baseline. In a second multivariable model, known potential confounders were included based on a literature search. Linear trends were assessed using biomarker levels on the $\log 2$ scale as continuous parameters in Cox regression models. Considering that serum levels of albumin, bilirubin and uric acid may be affected by manifest tumours, we conducted sensitivity analyses excluding cancer cases that had occurred during the first 2 years of follow-up from Cox regression models. SAS 9.4 (Cary, NC, USA) was used for all statistical analyses.

\section{RESULTS}

Characteristics of the study population. Characteristics of study participants in the random subcohort and those who developed cancer during the follow-up of EPIC-Heidelberg until 2009 are shown in Table 1. The subcohort consisted of 1466 women and 1273 men with mean ages of 49.5 and 52.6 at baseline. The average follow-up duration in the subcohort was $14.8( \pm 3.4)$ years. Follow-up durations among cases were as follows: colon cancer: 8.1 $( \pm 4.3)$ years; breast cancer: $8.4( \pm 4.5)$ years; lung cancer: 8.8 ( \pm 4.5$)$ years; prostate cancer: $9.2( \pm 4.4)$ years; cancer death: 7.5 $( \pm 3.7)$ years. While mean albumin levels only showed slight differences by case status or sex, mean bilirubin levels were higher 
Table 1. Characteristics of the study population (EPIC-Heidelberg, case-cohort sample)

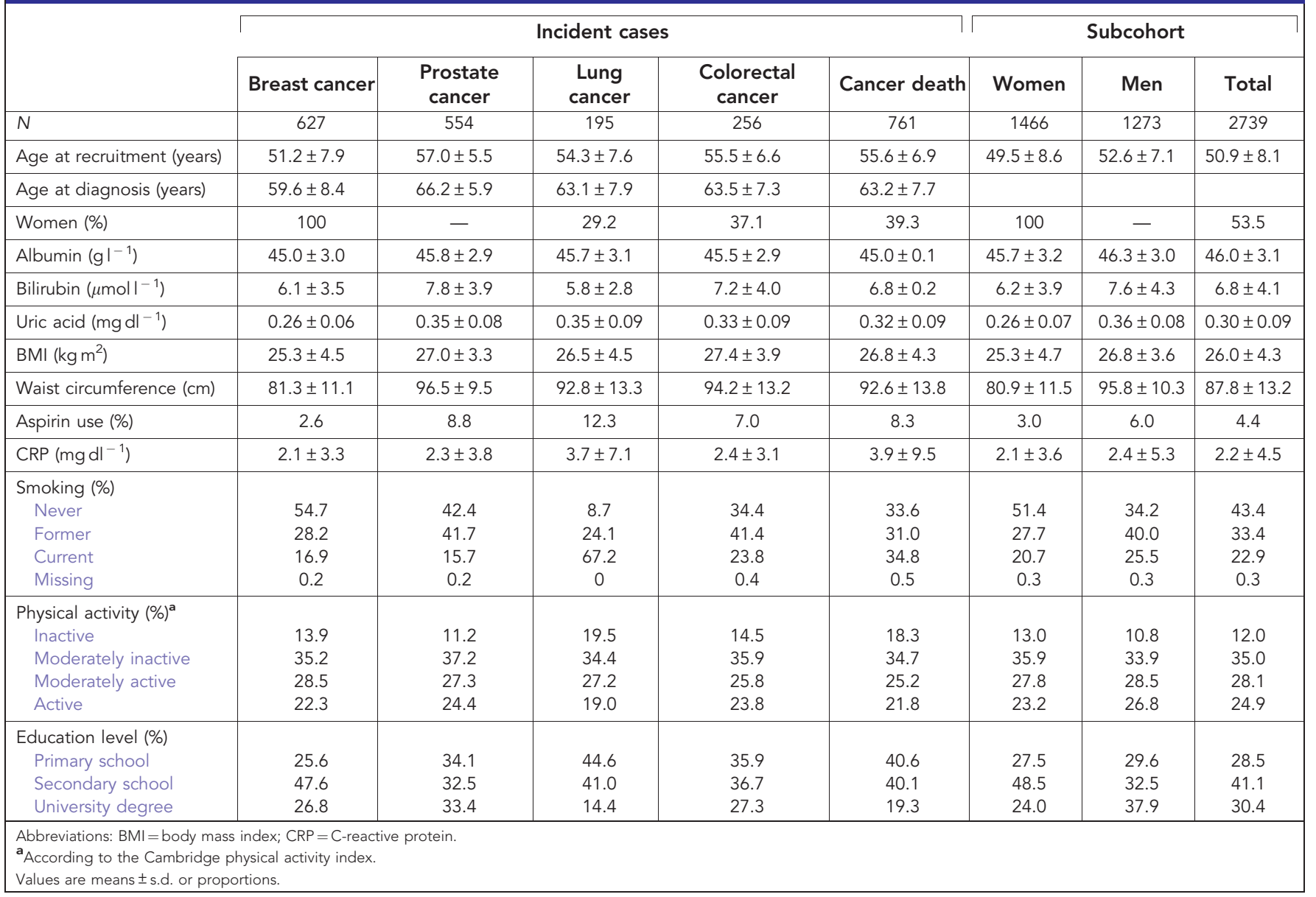

in men than in women, and lower in lung cancer cases. Uric acid levels were lower in women than in men too, but not different between cases and non-cases.

Further cross-sectional associations between antioxidant levels and potential confounding factors are presented in Supplementary Table 1. There were significant inverse associations between albumin concentrations and age, BMI as well as CRP levels. Bilirubin levels were lower with higher age, higher BMI, higher CRP and among smokers. Bilirubin levels were positively associated with alcohol intake and education level. Uric acid levels showed direct associations with age, smoking, BMI, alcohol intake as well as CRP, and were higher among individuals with lower educational degree and prevalent gout. Correlations between biomarker levels were weak, with Spearman's coefficients of 0.09 (albumin and uric acid), 0.05 (bilirubin and uric acid) and 0.16 (bilirubin and albumin).

Risk associations. Results of Cox regression analyses on antioxidant levels and cancer risk are shown in Tables $2 \mathrm{a}, 2 \mathrm{~b}$ and $2 \mathrm{c}$. In brief, albumin levels were significantly inversely associated with the

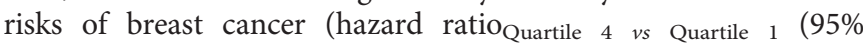
confidence interval): $\left.0.71(0.51,0.99), P_{\text {trend }}=0.004\right)$, and overall cancer mortality (HR: $\left.0.64(0.48,0.86), P_{\text {trend }}<0.001\right)$ after multivariable adjustment for potential confounders. There were no significant associations between albumin levels and the risks of lung, prostate and colorectal cancer. Uric acid levels were also associated with lower breast cancer risk (HR: $0.72(0.53,0.99)$, $\left.P_{\text {trend }}=0.043\right)$ and lower cancer mortality (HR: $0.75(0.58,0.98)$, $\left.P_{\text {trend }}=0.09\right)$, but not with the risks of lung, prostate and colorectal cancer. Results from analyses on uric acid and cancer risk were only marginally affected when prevalent gout was additionally included into the multivariable adjusted model as confounder; the HRs of breast cancer and cancer death were at $0.72(0.53,0.98)$, $P_{\text {trend }}=0.036$ and $0.74(0.57,0.97), P_{\text {trend }}=0.08$.

Considering the similarity of results for albumin and uric acid, that is, inverse associations with breast cancer risk and cancer mortality, further Cox regression analyses with mutual adjustments were carried out. Upon adjustment for uric acid levels, associations between albumin concentrations and breast cancer risk (HR: 0.69 $\left.(0.49,0.97), P_{\text {trend }}=0.004\right)$ as well as cancer mortality $(0.67(0.49$, $\left.0.89), P_{\text {trend }}<0.001\right)$ remained largely unchanged. The associations between uric acid and breast cancer risk (HR: $0.75(0.55,1.03)$, $\left.P_{\text {trend }}=0.09\right)$ and cancer mortality (HR: $0.81 \quad(0.62,1.05)$, $\left.P_{\text {trend }}=0.40\right)$ were slightly attenuated and no longer significant after adjustment for albumin.

Bilirubin levels were strongly inversely associated with lung cancer risk in the age- and sex-adjusted Cox model (HR: 0.31 $\left.(0.18,0.53), \quad P_{\text {trend }}<0.001\right)$. However, this association was attenuated by multivariable adjustment for confounders and did not remain statistically significant (HR: 0.56 (0.31, 1.02), $\left.P_{\text {trend }}=0.21\right)$. Bilirubin levels were not significantly associated with any of the other end points, either. An exclusion of study participants with impaired liver function (as defined by serum levels of glutamic oxaloacetic transaminase $>50 \mathrm{Ul}^{-1}$ ) did not affect the associations between bilirubin concentrations and cancer risks.

No significant interactions between biomarkers and adjustment factors were observed in Cox regression analyses. There was no indication for heterogeneity of associations between biomarkers and breast cancer risk by oestrogen receptor status. The exclusion 
Table 2a. Hazard ratios $(95 \% \mathrm{Cls})$ of cancer across quartiles of serum albumin

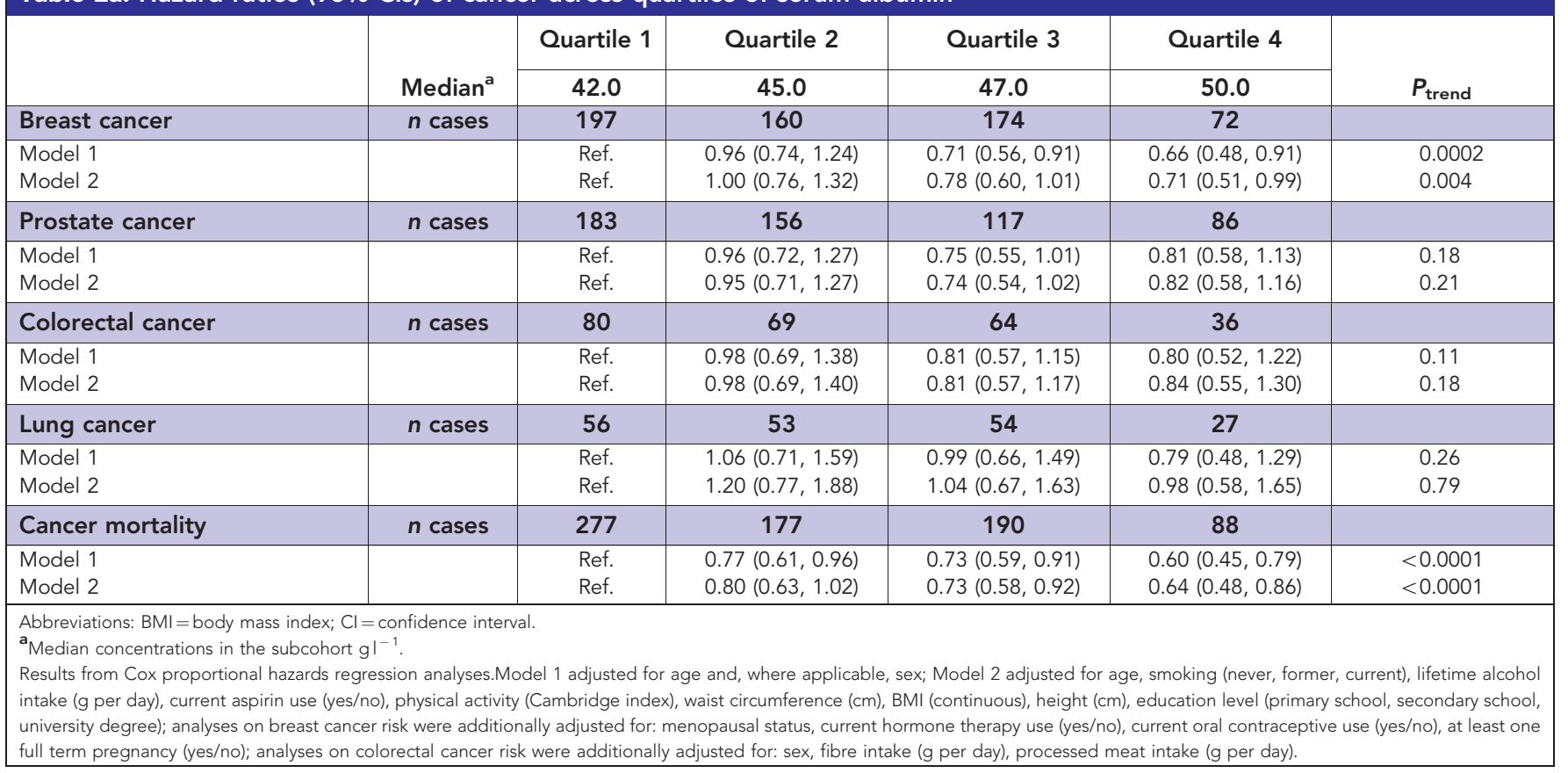

Table $2 \mathrm{~b}$. Hazard ratios $(95 \% \mathrm{Cls})$ of cancer across quartiles of serum bilirubin

\begin{tabular}{|c|c|c|c|c|c|c|}
\hline & Median $^{a}$ & Quartile 1 & Quartile 2 & Quartile 3 & Quartile 4 & $P_{\text {trend }}$ \\
\hline Breast cancer & $n$ cases & 207 & 98 & 133 & 132 & \\
\hline Model 2 & & Ref. & $1.04(0.77,1.40)$ & $1.12(0.85,1.48)$ & $1.15(0.87,1.52)$ & 0.57 \\
\hline Prostate cancer & $n$ cases & 160 & 84 & 157 & 113 & \\
\hline Model 1 & & Ref. & $0.94(0.67,1.30)$ & $1.05(0.79,1.39)$ & $1.31(0.96,1.80)$ & 0.12 \\
\hline Model 1 & & Ref. & $1.11(0.74,1.67)$ & $1.28(0.90,1.82)$ & $1.29(0.88,1.90)$ & 0.21 \\
\hline Model 2 & & Ref. & $1.14(0.75,1.74)$ & $1.33(0.91,1.93)$ & $1.40(0.93,2.09)$ & 0.14 \\
\hline Lung cancer & $n$ cases & 93 & 26 & 44 & 16 & \\
\hline Model 1 & & Ref. & $0.54(0.34,0.85)$ & $0.59(0.41,0.87)$ & $0.31(0.18,0.53)$ & $<0.0001$ \\
\hline Model 2 & & Ref. & $0.70(0.42,1.18)$ & $0.86(0.56,1.33)$ & $0.56(0.31,1.02)$ & 0.21 \\
\hline
\end{tabular}

of cancer cases that had occurred during the first 2 years of followup from risk analyses did not lead to substantial changes of the hazard ratios shown in Tables $2 \mathrm{a}, 2 \mathrm{~b}$ and $2 \mathrm{c}$. There was no heterogeneity of associations by lag time.

Analyses on cancer type-specific mortality were restricted due to lower case numbers (most common causes of cancer death: lung cancer, $n=138$; colorectal cancer, $n=78$; breast cancer, $n=69$; pancreatic cancer, $n=60$; prostate cancer, $n=29$ ). With respect to breast cancer mortality, we observed a linear trend for an inverse association with albumin, although there was no significant risk difference between women in the highest and the lowest quartile (HR: $\left.0.52(0.22,1.21), P_{\text {trend }}=0.006\right)$. Uric acid levels were not significantly associated with breast cancer mortality (HR: 0.57 $\left.(0.28,1.15), \quad P_{\text {trend }}=0.39\right)$. Albumin levels were significantly inversely associated with colorectal cancer mortality (HR: 0.44 $\left.(0.20,0.99), P_{\text {trend }}=0.006\right)$, while all other associations between the three biomarkers and cancer mortality by individual cause were non-significant.

\section{DISCUSSION}

In the present study, associations of pre-diagnostic serum albumin, bilirubin and uric acid with the risks of breast, prostate, lung and 
Table 2c. Hazard ratios ( $95 \% \mathrm{Cls}$ ) of cancer across quartiles of serum uric acid

\begin{tabular}{|c|c|c|c|c|c|c|}
\hline & \multirow[b]{2}{*}{ Median $^{a}$} & Quartile 1 & Quartile 2 & Quartile 3 & Quartile 4 & \multirow[b]{2}{*}{$P_{\text {trend }}$} \\
\hline & & 0.24 & 0.32 & 0.36 & 0.42 & \\
\hline Breast cancer & n cases & 165 & 136 & 165 & 111 & \\
\hline $\begin{array}{l}\text { Model } 1 \\
\text { Model } 2\end{array}$ & & $\begin{array}{l}\text { Ref. } \\
\text { Ref. }\end{array}$ & $\begin{array}{l}0.75(0.57,0.99) \\
0.77(0.57,1.02)\end{array}$ & $\begin{array}{l}0.81(0.62,1.06) \\
0.87(0.66,1.16)\end{array}$ & $\begin{array}{l}0.70(0.52,0.93) \\
0.72(0.53,0.99)\end{array}$ & $\begin{array}{l}0.01 \\
0.043\end{array}$ \\
\hline Prostate cancer & $n$ cases & 145 & 123 & 127 & 120 & \\
\hline $\begin{array}{l}\text { Model } 1 \\
\text { Model } 2\end{array}$ & & $\begin{array}{l}\text { Ref. } \\
\text { Ref. }\end{array}$ & $\begin{array}{l}0.99(0.73,1.35) \\
1.00(0.72,1.38)\end{array}$ & $\begin{array}{l}1.03(0.75,1.40) \\
1.06(0.76,1.47)\end{array}$ & $\begin{array}{l}0.98(0.72,1.33) \\
1.03(0.74,1.44)\end{array}$ & $\begin{array}{l}0.85 \\
0.94\end{array}$ \\
\hline Colorectal cancer & $n$ cases & 56 & 54 & 62 & 63 & \\
\hline $\begin{array}{l}\text { Model } 1 \\
\text { Model } 2\end{array}$ & & $\begin{array}{l}\text { Ref. } \\
\text { Ref. }\end{array}$ & $\begin{array}{l}1.01(0.68,1.50) \\
0.95(0.63,1.43)\end{array}$ & $\begin{array}{l}1.05(0.71,1.56) \\
1.00(0.67,1.50)\end{array}$ & $\begin{array}{l}1.14(0.77,1.67) \\
0.96(0.64,1.46)\end{array}$ & $\begin{array}{l}0.78 \\
0.54\end{array}$ \\
\hline Lung cancer & $n$ cases & 39 & 40 & 52 & 49 & \\
\hline $\begin{array}{l}\text { Model } 1 \\
\text { Model } 2\end{array}$ & & $\begin{array}{l}\text { Ref. } \\
\text { Ref. }\end{array}$ & $\begin{array}{l}1.14(0.72,1.81) \\
1.07(0.65,1.76)\end{array}$ & $\begin{array}{l}1.44(0.93,2.23) \\
1.27(0.79,2.05)\end{array}$ & $\begin{array}{l}1.42(0.91,2.23) \\
1.02(0.62,1.69)\end{array}$ & $\begin{array}{l}0.13 \\
0.14\end{array}$ \\
\hline Cancer mortality & $n$ cases & 200 & 143 & 186 & 174 & \\
\hline $\begin{array}{l}\text { Model } 1 \\
\text { Model } 2\end{array}$ & & $\begin{array}{l}\text { Ref. } \\
\text { Ref. }\end{array}$ & $\begin{array}{l}0.73(0.57,0.94) \\
0.69(0.53,0.90)\end{array}$ & $\begin{array}{l}0.88(0.69,1.11) \\
0.84(0.65,1.08)\end{array}$ & $\begin{array}{l}0.87(0.68,1.11) \\
0.75(0.58,0.98)\end{array}$ & $\begin{array}{l}0.16 \\
0.09\end{array}$ \\
\hline \multicolumn{7}{|c|}{$\begin{array}{l}\text { Abbreviations: } \mathrm{BMI}=\text { body mass index; } \mathrm{Cl}=\text { confidence interval. } \\
{ }^{\mathrm{a}} \text { Median concentrations in the subcohort } \mathrm{mg} \mathrm{dl}^{-1} \text {. } \\
\text { Results from Cox proportional hazards regression analyses.Model } 1 \text { adjusted for age and, where applicable, sex.Model } 2 \text { adjusted for age, smoking (never, former, current), lifetime alcohol } \\
\text { intake (g per day), current aspirin use (yes/no), physical activity (Cambridge index), waist circumference ( } \mathrm{cm}), \mathrm{BMl} \text { (continuous), height (cm), education level (primary school, secondary school, } \\
\text { university degree); analyses on breast cancer risk were additionally adjusted for: menopausal status, current hormone therapy use (yes/no), current oral contraceptive use (yes/no), at least one } \\
\text { full term pregnancy (yes/no); analyses on colorectal cancer risk were additionally adjusted for: sex, fibre intake (g per day), processed meat intake (g per day). }\end{array}$} \\
\hline
\end{tabular}

colorectal cancer as well as total cancer death were analysed using data of the prospective EPIC-Heidelberg cohort. Both albumin and uric acid levels were inversely associated with breast cancer risk and cancer mortality in multivariable statistical models, while there were no significant associations with risks of lung, prostate and colon cancer. No significant associations between bilirubin levels and any of the cancer end points were observed.

Our finding of an inverse association between pre-diagnostic albumin levels and breast cancer risk is not in line with a recent finding from the registry-based Swedish AMORIS study, which showed no significant association (Wulaningsih et al, 2015). Just like in our study, there was no significant association between albumin and prostate cancer risk in the AMORIS study (Van Hemelrijck et al, 2011), even though the hazard ratios of 0.79 for participants in the highest albumin quartile in both studies may still be compatible with a weaker inverse relationship. With respect to colon cancer risk, two earlier publications of longitudinal survey data from the United States had shown inverse associations with albumin levels (Stevens et al, 1988; Ko et al, 1994), whereas no significant associations were observed in a registry-based cohort from Finland (Knekt et al, 2000) and the population-based ARIC study (Prizment et al, 2011). Only recently, a weak inverse relationship between albumin and colon cancer risk was reported from the AMORIS study (Ghuman et al, 2017). Overall, these previous results and the non-significant inverse association in our study may again point to a weak inverse association between albumin and colon cancer risk. The lack of association between albumin concentrations and risk of lung cancer in our study is consistent with a report from a community-based American cohort (Sprague et al, 2008). Finally, our result of lower albumin levels being related to greater risk of cancer death is in line with two smaller studies from the early 1990s (Phillips et al, 1989; KlonoffCohen et al, 1992), and one recent metabolomics study, in which albumin was among the four 'top hits' out of 106 lipids, proteins and metabolites showing the strongest associations with cancer mortality (Fischer et al, 2014).

A decrease in circulating albumin in cancer patients has been known for decades ([No Authors listed], 1972; Costa, 1977) and lower albumin levels are consistently related to worse prognosis with respect to various tumour types (Gupta and Lis, 2010). Reasons for lower albumin levels in cancer patients include an inhibition of albumin synthesis due to cancer-related systemic inflammation, malnutrition and an increased turnover of albumin by tumours (Stehle et al, 1997; Gupta and Lis, 2010). Associations between pre-diagnostic albumin levels many years prior to diagnosis and cancer risk may not be fully explained by these phenomena, however, considering that the results of the present study were independent of CRP status and lag time between blood collection and diagnosis. Thus, the hypothesis of anti-oxidative properties of albumin (Ko et al, 1994) may remain plausible, despite limited mechanistic data regarding cancer. Strikingly, recent data from a large-scale cross-sectional study on the relationship between a wide range of routine blood biochemistry markers and chronological age revealed that albumin was clearly most predictive of age (Putin et al, 2016). When further considering that albumin has also been shown to be inversely associated with cardiovascular disease risk and mortality (Danesh et al, 1998; Putin et al, 2016), it seems equally possible that albumin either exerts global anti-oxidative or anti-inflammatory effects or that it is an unspecific marker of biological age, lifestyle and overall health status. In our study, albumin levels were inversely associated with age, BMI and CRP levels, even though adjustment for these factors hardly affected risk associations. Eventually, a straightforward way to further investigate whether associations between albumin levels and chronic diseases reflect causal relationships could be Mendelian randomisation, as genetic proxies for serum albumin have been identified (Franceschini et al, 2012; Kettunen et al, 2012).

With respect to bilirubin levels, we observed a strong inverse association with lung cancer risk that was attenuated when correcting for confounders, particularly smoking status, and remained no longer significant in the multivariable Cox regression model. By contrast, higher bilirubin levels remained significantly associated with lower lung cancer risk in previous large-scale studies from the United Kingdom (Horsfall et al, 2011) and Taiwan (Wen et al, 2015) after adjustment for smoking. Interestingly, bilirubin levels were significantly lower in smokers than in non-smokers in these studies and in our study, possibly 
indicating that residual confounding due to an imperfect assessment of smoking status could be underlying bilirubin lung cancer relationships, and that lower bilirubin levels are an epiphenomenon of smoking. Yet, both the Taiwanese and the British study, for which comprehensive medical care databases were used, included higher case numbers than ours, and the hazard ratio of lung cancer in our study $(0.58(0.32,1.05))$ may still be in line with the notion of a somewhat lower lung cancer risk at higher bilirubin levels.

For uric acid, our analyses showed an inverse association with breast cancer risk. Similarly, lower breast cancer risk was observed among women in the highest quartile of uric acid levels in the AMORIS study (Yiu et al, 2017). These results are opposed to a null finding from a large North American cohort (Hiatt and Fireman, 1988), and to the observation of a direct association between uric acid and breast cancer-related death from an Austrian cohort (Strasak et al, 2007). In the later study, a recent meta-analysis (Yan et al, 2015), and a recent Mendelian randomisation study from Denmark (Kobylecki et al, 2017), uric acid levels and overall cancer mortality were directly associated, which is contrast to our present finding of an inverse association. Our null result regarding colon cancer risk is in line with the result of a previous prospective study (Ko et al, 1994), whereas higher uric acid levels were related to a significantly higher risk of colorectal cancer in the AMORIS study (Yiu et al, 2017). As in our study, uric acid levels were not significantly associated with prostate cancer risk in AMORIS (Yiu et al, 2017). While the AMORIS study further suggested lower risk of pulmonary cancers among men, but higher risk among women with higher uric acid, analyses based on prospective data from a British primary care database revealed higher risk of lung cancer with higher uric acid only among smokers (Horsfall et al, 2014). Overall, the evidence on a link between uric acid and cancer risk appears to be rather heterogeneous, although it is notable that the inverse associations with breast cancer and cancer death remained statistically significant in our study, despite uric acid levels being related to a less favourable pattern of lifestyle factors, higher CRP levels and an older age. It is also remarkable, that both uric acid and albumin levels were significantly associated with breast cancer risk and cancer mortality, but not with the risks of prostate, colorectal or lung cancer in our study. If the anti-oxidative potential of albumin and uric acid underlay the observed associations for breast cancer and cancer mortality, one could have expected that such a more global mechanism drives similar associations with other cancer end points. In this regard, we are not aware of strong experimental evidence to indicate that albumin or uric acid should have a specific role in the development of breast cancer.

The present study had several limitations. Blood biochemistry markers were only available from one time point. However, it is not likely that the routine markers analysed in the present study undergo substantial intra-individual changes over time (Al-Delaimy et al, 2006). Unlike in the majority of previous studies that were based on registry, survey or primary care data, we could comprehensively adjust for lifestyle factors and other potential confounders, which may explain some of the null associations from our analyses. At the same time, we cannot rule out residual confounding with respect to the observed significant associations, despite adjustment for background factors. Finally, the number of incident cases could have been too low to detect weaker associations, for example, between albumin levels and colorectal cancer risk. Analyses on mortality by cancer type were restricted due to low case numbers.

\section{CONCLUSION}

In the EPIC-Heidelberg study, serum levels of albumin and uric acid were significantly inversely associated with breast cancer risk and overall cancer mortality, but not with the risks of lung, prostate and colorectal cancer. Bilirubin levels were not associated with any cancer end point. Our results are in line with the notion of antioxidative effects of albumin and uric acid to inhibit breast carcinogenesis. Nevertheless, we have to acknowledge that associations between albumin, and especially uric acid, with cancer risk in epidemiological studies have been heterogeneous, and that stronger experimental evidence is needed to corroborate hypotheses on potential anti-carcinogenic properties of albumin and uric acid.

\section{ACKNOWLEDGEMENTS}

The EPIC-Heidelberg study was sponsored by the German Federal Ministry of Education and Research (grant no. 01ER0809) and the German Cancer Research Center (DKFZ). The present analysis was further supported by the Helmholtz Association of German Research Centres (portfolio theme: metabolic dysfunction).

\section{CONFLICT OF INTEREST}

The authors declare no conflict of interest.

\section{REFERENCES}

[No Authors listed] (1972) Cancer and albumin metabolism. Nutr Rev 30(7): 170-172.

Al-Delaimy WK, Jansen EH, Peeters PH, van der Laan JD, van Noord PA, Boshuizen HC, van der Schouw YT, Jenab M, Ferrari P, Bueno-de-Mesquita HB (2006) Reliability of biomarkers of iron status, blood lipids, oxidative stress, vitamin D, C-reactive protein and fructosamine in two Dutch cohorts. Biomarkers 11(4): 370-382.

Ames BN, Cathcart R, Schwiers E, Hochstein P (1981) Uric acid provides an antioxidant defense in humans against oxidant- and radical-caused aging and cancer: a hypothesis. Proc Natl Acad Sci USA 78(11): 6858-6862.

Bergmann MM, Bussas U, Boeing H (1999) Follow-up procedures in EPIC-Germany-data quality aspects. European prospective investigation into cancer and nutrition. Ann Nutr Metab 43(4): 225-234.

Boeing H, Wahrendorf J, Becker N (1999) EPIC-Germany-a source for studies into diet and risk of chronic diseases. European investigation into cancer and nutrition. Ann Nutr Metab 43(4): 195-204.

Ching S, Ingram D, Hahnel R, Beilby J, Rossi E (2002) Serum levels of micronutrients, antioxidants and total antioxidant status predict risk of breast cancer in a case control study. J Nutr 132(2): 303-306.

Costa G (1977) Cachexia, the metabolic component of neoplastic diseases. Cancer Res 37(7 Pt 2): 2327-2335.

Danesh J, Collins R, Appleby P, Peto R (1998) Association of fibrinogen, C-reactive protein, albumin, or leukocyte count with coronary heart disease: meta-analyses of prospective studies. JAMA 279(18): $1477-1482$.

Dziaman T, Banaszkiewicz Z, Roszkowski K, Gackowski D, Wisniewska E, Rozalski R, Foksinski M, Siomek A, Speina E, Winczura A, Marszalek A, Tudek B, Olinski R (2014) 8-Oxo-7,8-dihydroguanine and uric acid as efficient predictors of survival in colon cancer patients. Int $J$ Cancer 134(2): 376-383.

Fischer K, Kettunen J, Wurtz P, Haller T, Havulinna AS, Kangas AJ, Soininen P, Esko T, Tammesoo ML, Magi R, Smit S, Palotie A, Ripatti S, Salomaa V, Ala-Korpela M, Perola M, Metspalu A (2014) Biomarker profiling by nuclear magnetic resonance spectroscopy for the prediction of all-cause mortality: an observational study of 17345 persons. PLoS Med 11(2): e1001606.

Franceschini N, van Rooij FJ, Prins BP, Feitosa MF, Karakas M, Eckfeldt JH, Folsom AR, Kopp J, Vaez A, Andrews JS, Baumert J, Boraska V, Broer L, Hayward C, Ngwa JS, Okada Y, Polasek O, Westra HJ, Wang YA, Del Greco MF, Glazer NL, Kapur K, Kema IP, Lopez LM, Schillert A, Smith AV, Winkler CA, Zgaga L, Bandinelli S, Bergmann S, Boban M, 
Bochud M, Chen YD, Davies G, Dehghan A, Ding J, Doering A, Durda JP, Ferrucci L, Franco OH, Franke L, Gunjaca G, Hofman A, Hsu FC, Kolcic I, Kraja A, Kubo M, Lackner KJ, Launer L, Loehr LR, Li G, Meisinger C, Nakamura Y, Schwienbacher C, Starr JM, Takahashi A, Torlak V, Uitterlinden AG, Vitart V, Waldenberger M, Wild PS, Kirin M, Zeller T, Zemunik T, Zhang Q, Ziegler A, Blankenberg S, Boerwinkle E, Borecki IB, Campbell H, Deary IJ, Frayling TM, Gieger C, Harris TB, Hicks AA, Koenig W, O’ Donnell CJ, Fox CS, Pramstaller PP, Psaty BM, Reiner AP, Rotter JI, Rudan I, Snieder H, Tanaka T, van Duijn CM, Vollenweider P, Waeber G, Wilson JF, Witteman JC, Wolffenbuttel BH, Wright AF, Wu Q, Liu Y, Jenny NS, North KE, Felix JF, Alizadeh BZ, Cupples LA, Perry JR, Morris AP (2012) Discovery and fine mapping of serum protein loci through transethnic meta-analysis. Am J Hum Genet 91(4): 744-753.

Gao C, Fang L, Li JT, Zhao HC (2016) Significance and prognostic value of increased serum direct bilirubin level for lymph node metastasis in Chinese rectal cancer patients. World J Gastroenterol 22(8): 2576-2584.

Ghuman S, Van Hemelrijck M, Garmo H, Holmberg L, Malmstrom H, Lambe M, Hammar N, Walldius G, Jungner I, Wulaningsih W (2017) Serum inflammatory markers and colorectal cancer risk and survival. $\mathrm{Br} J$ Cancer 116(10): 1358-1365.

Gupta D, Lis CG (2010) Pretreatment serum albumin as a predictor of cancer survival: a systematic review of the epidemiological literature. Nutr J 9: 69.

Haas M, Heinemann V, Kullmann F, Laubender RP, Klose C, Bruns CJ, Holdenrieder S, Modest DP, Schulz C, Boeck S (2013) Prognostic value of CA 19-9, CEA, CRP, LDH and bilirubin levels in locally advanced and metastatic pancreatic cancer: results from a multicenter, pooled analysis of patients receiving palliative chemotherapy. J Cancer Res Clin Oncol 139(4): 681-689.

Halliwell B (1988) Albumin—an important extracellular antioxidant? Biochem Pharmacol 37(4): 569-571.

Hiatt RA, Fireman BH (1988) Serum uric acid unrelated to cancer incidence in humans. Cancer Res 48(10): 2916-2918.

Horsfall LJ, Nazareth I, Petersen I (2014) Serum uric acid and the risk of respiratory disease: a population-based cohort study. Thorax 69(11): 1021-1026.

Horsfall LJ, Rait G, Walters K, Swallow DM, Pereira SP, Nazareth I, Petersen I (2011) Serum bilirubin and risk of respiratory disease and death. JAMA 305(7): 691-697.

Ioannou GN, Liou IW, Weiss NS (2006) Serum bilirubin and colorectal cancer risk: a population-based cohort study. Aliment Pharmacol Ther 23(11): $1637-1642$.

Kettunen J, Tukiainen T, Sarin AP, Ortega-Alonso A, Tikkanen E, Lyytikainen LP, Kangas AJ, Soininen P, Wurtz P, Silander K, Dick DM, Rose RJ, Savolainen MJ, Viikari J, Kahonen M, Lehtimaki T, Pietilainen KH, Inouye M, McCarthy MI, Jula A, Eriksson J, Raitakari OT, Salomaa V, Kaprio J, Jarvelin MR, Peltonen L, Perola M, Freimer NB, Ala-Korpela M, Palotie A, Ripatti S (2012) Genome-wide association study identifies multiple loci influencing human serum metabolite levels. Nat Genet 44(3): 269-276.

Klonoff-Cohen H, Barrett-Connor EL, Edelstein SL (1992) Albumin levels as a predictor of mortality in the healthy elderly. J Clin Epidemiol 45(3): 207-212.

Knekt P, Hakulinen T, Leino A, Heliovaara M, Reunanen A, Stevens R (2000) Serum albumin and colorectal cancer risk. Eur J Clin Nutr 54(6): $460-462$.

Ko WF, Helzlsouer KJ, Comstock GW (1994) Serum albumin, bilirubin, and uric acid and the anatomic site-specific incidence of colon cancer. J Natl Cancer Inst 86(24): 1874-1875.

Kobylecki CJ, Afzal S, Nordestgaard BG (2017) Plasma urate, cancer incidence, and all-cause mortality: a Mendelian randomization study. Clin Chem 63(6): 1151-1160.

Kolonel LN, Yoshizawa C, Nomura AM, Stemmermann GN (1994) Relationship of serum uric acid to cancer occurrence in a prospective male cohort. Cancer Epidemiol Biomarkers Prev 3(3): 225-228.

Lin H, Lin HX, Ge N, Wang HZ, Sun R, Hu WH (2013) Plasma uric acid and tumor volume are highly predictive of outcome in nasopharyngeal carcinoma patients receiving intensity modulated radiotherapy. Radiat Oncol 8: 121 .

Liu X, Meng QH, Ye Y, Hildebrandt MA, Gu J, Wu X (2015) Prognostic significance of pretreatment serum levels of albumin, $\mathrm{LDH}$ and total bilirubin in patients with non-metastatic breast cancer. Carcinogenesis 36(2): 243-248.

Phillips A, Shaper AG, Whincup PH (1989) Association between serum albumin and mortality from cardiovascular disease, cancer, and other causes. Lancet 2(8677): 1434-1436.

Prentice RL (1986) A case-cohort design for epidemiologic cohort studies and disease prevention trials. Biometrika 73(1): 1-11.

Prizment AE, Anderson KE, Visvanathan K, Folsom AR (2011) Association of inflammatory markers with colorectal cancer incidence in the atherosclerosis risk in communities study. Cancer Epidemiol Biomarkers Prev 20(2): 297-307.

Putin E, Mamoshina P, Aliper A, Korzinkin M, Moskalev A, Kolosov A, Ostrovskiy A, Cantor C, Vijg J, Zhavoronkov A (2016) Deep biomarkers of human aging: application of deep neural networks to biomarker development. Aging 8(5): 1021-1033.

Riboli E, Kaaks R (1997) The EPIC project: rationale and study design. European prospective investigation into cancer and nutrition. Int $J$ Epidemiol 26(Suppl 1): S6-S14.

Shin HS, Lee HR, Lee DC, Shim JY, Cho KH, Suh SY (2006) Uric acid as a prognostic factor for survival time: a prospective cohort study of terminally ill cancer patients. J Pain Symptom Manage 31(6): 493-501.

Sprague BL, Trentham-Dietz A, Klein BE, Klein R, Cruickshanks KJ, Lee KE, Hampton JM (2008) Physical activity, white blood cell count, and lung cancer risk in a prospective cohort study. Cancer Epidemiol Biomarkers Prev 17(10): 2714-2722.

Stehle G, Sinn H, Wunder A, Schrenk HH, Stewart JC, Hartung G, Maier-Borst W, Heene DL (1997) Plasma protein (albumin) catabolism by the tumor itself-implications for tumor metabolism and the genesis of cachexia. Crit Rev Oncol Hematol 26(2): 77-100.

Stevens RG, Jones DY, Micozzi MS, Taylor PR (1988) Body iron stores and the risk of cancer. N Engl J Med 319(16): 1047-1052.

Stocker R, Yamamoto Y, McDonagh AF, Glazer AN, Ames BN (1987) Bilirubin is an antioxidant of possible physiological importance. Science 235(4792): 1043-1046.

Stotz M, Szkandera J, Seidel J, Stojakovic T, Samonigg H, Reitz D, Gary T, Kornprat P, Schaberl-Moser R, Hoefler G, Gerger A, Pichler M (2014) Evaluation of uric acid as a prognostic blood-based marker in a large cohort of pancreatic cancer patients. PLoS One 9(8): e104730.

Strasak AM, Lang S, Kneib T, Brant LJ, Klenk J, Hilbe W, Oberaigner W, Ruttmann E, Kaltenbach L, Concin H, Diem G, Pfeiffer KP, Ulmer H (2009) Use of penalized splines in extended Cox-type additive hazard regression to flexibly estimate the effect of time-varying serum uric acid on risk of cancer incidence: a prospective, population-based study in 78,850 men. Ann Epidemiol 19(1): 15-24.

Strasak AM, Rapp K, Hilbe W, Oberaigner W, Ruttmann E, Concin H, Diem G, Pfeiffer KP, Ulmer H (2007) The role of serum uric acid as an antioxidant protecting against cancer: prospective study in more than 28000 older Austrian women. Ann Oncol 18(11): 18931897.

Temme EH, Zhang J, Schouten EG, Kesteloot H (2001) Serum bilirubin and 10 -year mortality risk in a Belgian population. Cancer Causes Control 12(10): 887-894.

Van Hemelrijck M, Jungner I, Walldius G, Garmo H, Binda E, Hayday A, Lambe M, Holmberg L, Hammar N (2011) Risk of prostate cancer is not associated with levels of C-reactive protein and other commonly used markers of inflammation. Int J Cancer 129(6): $1485-1492$.

Wen CP, Zhang F, Liang D, Wen C, Gu J, Skinner H, Chow WH, Ye Y, $\mathrm{Pu}$ X, Hildebrandt MA, Huang M, Chen CH, Hsiung CA, Tsai MK, Tsao CK, Lippman SM, Wu X (2015) The ability of bilirubin in identifying smokers with higher risk of lung cancer: a large cohort study in conjunction with global metabolomic profiling. Clin Cancer Res 21(1): 193-200.

Wulaningsih W, Holmberg L, Garmo H, Malmstrom H, Lambe M, Hammar N, Walldius G, Jungner I, Van Hemelrijck M (2015) Prediagnostic serum inflammatory markers in relation to breast cancer risk, severity at diagnosis and survival in breast cancer patients. Carcinogenesis 36(10): 1121-1128.

Xue X, Xie X, Gunter M, Rohan TE, Wassertheil-Smoller S, Ho GY, Cirillo D, Yu H, Strickler HD (2013) Testing the proportional hazards assumption in case-cohort analysis. BMC Med Res Methodol 13: 88. 
Yan S, Zhang P, Xu W, Liu Y, Wang B, Jiang T, Hua C, Wang X, Xu D, Sun B (2015) Serum uric acid increases risk of cancer incidence and mortality: a systematic review and meta-analysis. Mediators Inflamm 2015: 764250.

Yiu A, Van Hemelrijck M, Garmo H, Holmberg L, Malmstrom H, Lambe M, Hammar N, Walldius G, Jungner I, Wulaningsih W (2017) Circulating uric acid levels and subsequent development of cancer in 493,281 individuals: findings from the AMORIS Study. Oncotarget 8(26): 4233242342 .
Zucker SD, Horn PS, Sherman KE (2004) Serum bilirubin levels in the U.S. population: gender effect and inverse correlation with colorectal cancer. Hepatology 40(4): 827-835.

This work is published under the standard license to publish agreement. After 12 months the work will become freely available and the license terms will switch to a Creative Commons AttributionNonCommercial-Share Alike 4.0 Unported License.

Supplementary Information accompanies this paper on British Journal of Cancer website (http://www.nature.com/bjc) 